\title{
Predictive role of caregiver type, dependency level and time caring on the impact of caring for a dependent relative as a stressor
}

\author{
Teresa Lanzón Serra ${ }^{1,2}$ and Amelia Díaz Martínez ${ }^{1}$ \\ ${ }^{1}$ University of Valencia (Spain); \\ ${ }^{2}$ University Hospital of Valencia (Spain)
}

\begin{abstract}
This work presents the evaluation of the stress symptoms associated to the task of caring for a dependent relative at home. The role played by variables such as type of caregiver (nurse/non-nurse), the relative dependency level, the number of hours per day dedicated to caring and the years the caregiver had been caring for the relative was studied. The sample was made up of 100 caregivers, and the variables associated to stress studied in the present work were intrusion, avoidance and activation. Results showed that non-nurse caregivers caring for a low dependency relative for a period of less than two years were those suffering a higher impact, with more symptoms associated to stress. Hours caring per day worked as a protective variable of stress, in that those caregivers dedicating a lower number of hours to caring had lower risk of suffering stress symptoms. These results clearly show the stressful impact of the first stages of dependency, even at the lowest level of dependency in a relative, on non-professional caregivers and highlight the need to provide strategies, similar to those shown by professional nurses looking after their own relatives, to reduce stress. This kind of intervention would prepare the caregiver for the future stages when the dependency level in the relatives and the effort caring for them would be higher.
\end{abstract}

Keywords: Stress, type of caregiver, dependency level, hours caring, years caring.

Papel predictor de las variables tipo de cuidador, nivel de dependencia y tiempo dedicado al cuidado en el impacto del estresor: cuidar a un familiar dependiente. El trabajo presenta la evaluación de sintomatología de estrés asociada a la tarea de cuidar a un familiar dependiente en el hogar. Se estudia el papel que desempeñan variables como el tipo de cuidador (enfermero/no enfermero), nivel de dependencia de la persona cuidada, horas al día de cuidado y años que se lleva cuidando al familiar. La muestra está compuesta por 100 cuidadores y las variables asociadas a estrés son intrusión, evitación y activación. Los resultados indican que los no enfermeros, que cuidan a un familiar con un nivel de dependencia bajo y durante menos de dos años son aquellos con mayor sintomatología asociada al estrés, donde el impacto del cuidado parece ser mayor. Horas de cuidado funciona como una variable protectora de estrés en el sentido de que a menos horas de cuidado, menos probabilidad de sufrir estrés. Los resultados llaman la atención sobre el estrés sufrido en las primeras etapas en la tarea del cuidado, cuando el familiar todavía tiene niveles bajos de dependencia, y la necesidad de suministrar estrategias que parecen poseer los enfermeros a través de una intervención que pueda reducir el estrés y prepare al cuidador para posteriores etapas en las que la dependencia de la persona cuidada y el esfuerzo en su cuidado sea mayor.

Palabras clave: Estrés, tipo de cuidador, dependencia, horas de cuidado, años cuidando.

Correspondence: Amelia Díaz Martínez. University of Valencia. Faculty of Psychology. Avd. Blasco Ibañez, 21. C.P.: 46019. Valencia (Spain). E-mail: Amelia.diaz@uv.es 
In Spain ninety per cent of dependents older than 65 years are looked after by their own families (Roguero, 2008). Spain, as a Mediterranean country, possesses a culture where the family provides an important support, not only in childhood, when grandparents act as informal caregivers, but also in the opposite direction, when the elderly members are the recipient of care.

Many psychological variables have been studied in informal caregivers looking after dependent relatives, depression, anxiety and hostility being the most representative (Langa, Ariza, Martínez \& Olid, 2009; Segui, Ortiz \& de Diego, 2008). However, among the psychological variables, burden, together with the perceived stress associated to caregiving, are the most important in the short term. Thus, Buck, Gregson, Bamford, McNamee, Farrow, Bond and Wright (1997), and Golimbert \& Trubnikov (2001) attributed the worse health of caregivers as compared to non-caregivers directly to stress. A variable that is on the basis of the higher stress levels in caregivers is the type of condition of the care recipient, so that caregivers who look after people suffering from neurodegenerative diseases show higher levels of stress, anxiety, depression and worse physical health than other type of caregivers (Artaso, Goñi \& Biorrun, 2003). A final set of factors that seem to influence the poorer health and higher stress levels perceived by the caregiver are directly associated with the caregivers themselves (age of the caregiver, the hours per day dedicated to caregiving or the years the caregiver has been performing this role), or with the physical demands of the task of looking after the dependent relative (Schultz \& Beach, 1999).

There seems to be at the moment a coexistence between models that predict a worsening in the level of caregiver stress, with the consequent deterioration of the caregiver physical and mental health as the dependency and the need for care by the care recipient increases, with models that point towards an initial stage of stress in the early stages of caregiving with a progressive adaptation over time (Lavoie, 1995, Morris \& Morris, 1993), with lower levels of stress as the caregiver adapts to the care situation.

The kind of interventions more often used in caregivers caring for a dependent relative are based on relief, educative and psychotherapeutic programs, with interdisciplinary programs using health personnel concentration mainly on providing the caregiver with specific formation in the illness of the dependent relative and giving the caregiver the pharmacologic prescription required (Ortiz \& Lozano, 2005; Guerra \& Zambrano, 2013). This is perhaps due to the association between caregiver and patient care that healthcare professionals automatically make; they perceive the caregiver as a resource rather than a patient in need of care and not just medication. The problems of loneliness and low quality of life of caregivers are clearly perceived by medical personnel that perform home health care, but its educational function appears to be restricted to the illness of the care recipient and rarely to the health of the caregiver (Delicado, Candel, Alfaro, López \& García, 2013). 
In this context, the present study tries to clarify the role of four specific variables, the qualification of the caregiver (nurse/non-nurse); hours per day dedicated to caring; years caring and the dependency level of the dependent relative, in the symptoms of stress showed by the caregivers.

\section{METHOD}

\section{Participants}

The sample was made up of 100 participants, all of them the main caregivers of dependent relatives receiving home health services, with ages ranging from 42 to 60 years and a mean 52.15 years of age. Most of them were women (75\%), married or with a partner (74\%) performing paid jobs outside home $(86 \%)$. The care recipient age was over 60 years in $72 \%$ of cases. They were close relatives and the most frequent health conditions they suffered were cancer $(33 \%)$ and degenerative neurological disease (20\%). Other illnesses suffered by the remaining $47 \%$ were coronary, endocrine, digestive, renal and degenerative bone diseases.

Sample features are shown in table 1. All participants cared for a dependent relative at home, but half were nurses working in different Hospitals in Valencia City, whilst the remaining half worked in jobs not related to health or care services. So, taking into account the job performed by the whole sample, $50 \%$ of caregivers had received training in assistance and caring tasks and $50 \%$ of caregivers had received no training at all. The dependency level of the person taken care of was high in $40 \%$ of cases. The hours of care provided by the caregiver ranged from 1 to 15 hours a day, although the majority (62\%) provided between 1 to 3 hours a day of caring. Finally, the years caring for the dependent relative ranged from 1 to 23 years, $55 \%$ of the sample being in the range of 1-2 years in the duty of care. The hours and years of care and level of dependency variables led to dichotomous variables by dividing the sample into two groups using the median as the cutoff point in the first two variables and the score of 60 in the dependency variable, as shown in Barthel scale (Mahoney \& Barthel, 1965; Baztan González \& del Ser, 1994, in the Spanish adaptation) to separate low dependent relatives $(\geq 60)$ from high dependent relatives $(<60)$.

Table 1. Sample description

\begin{tabular}{lcc}
\hline & & $N(\%)$ \\
\hline \multirow{2}{*}{ Type of caregiver } & Nurses & $50(50)$ \\
& Non-nurses & $50(50)$ \\
\hline \multirow{2}{*}{ Hours caring a day } & $1-3$ hours & $62(62)$ \\
& $\geq 4$ hours & $38(38)$ \\
\multirow{2}{*}{ Years caring } & $<2$ years & $55(55)$ \\
& $\geq 2$ years & $45(45)$ \\
\hline \multirow{2}{*}{ Dependency level of care recipient } & Low & $60(60)$ \\
& High & $40(40)$ \\
\hline
\end{tabular}




\section{Instruments}

Demographic Data. Caregivers gave first data on their age, gender, marital status, education level and paid work done and then they provided information about the relative they cared for, such as hours per day devoted to caring each, years caring and the medical conditions of the dependent relative.

The Barthel Activities of Daily Living Index (ADL) provides a measure on functional dependency level. It was developed by Mahoney \& Barthel in 1965 and adapted to the Spanish population by Batzan et al. (1994). It is one of the most used scales in the assessment of functional dependence. It rates dependence of the participant through a score ranging from 1 to 100 , with high scores indicative of low dependency and low scores indicative of high functional dependence. In this study the scale has been filled by the caregiver, and the scores have been reversed to get a final variable of dependence. Therefore, high scores indicate high dependence and low scores low dependence. The areas explored were: climbing stairs, walking, transfer from chair to bed, feeding, dressing, bathing, toilet use, grooming, urinary incontinence and fecal incontinence. The reliability obtained in this study is high (Cronbach Alpha=.94).

Impact of Event Scale (IES-R) was developed by Horowitz, Wilner \& Alvarez, (1979) and it was adapted to Spanish population by Báguena, Villarroya, Beleña, Díaz \& Reig (2001). It is made up of 22 items with four answer choices (none, little, quite, a lot). It was completed by the caregiver and assessed the impact of the stressor, caring for the dependent relative, in the last 7 days through three variables: intrusion, avoidance and arousal. The reliability in this study using Cronbach Alpha has been: intrusion=.97; avoidance $=.95$ and activation $=.96$.

\section{Procedure}

One of the authors of the study, a nurse involved in the home health service, carried out the measurement of the variables at the caregivers' home and at various hospitals after the end of the workday in the case of nurses. The study was advertised on bulletin boards of hospitals with phones and emails of the authors as a means of contact. Consent was obtained from both the hospitals and the individuals participating in the study.

\section{Statistical Analysis}

Analysis focused on the calculation of the reliability in the form of internal consistency. Mean differences analysis, using ANOVA and statistical " $d$ " of Cohen for effect size in intrusion, avoidance and arousal between different groups of caregivers (nurses/non nurses, low dependency/ high dependency level in the relative, 1 to 3 hours of daily care/4 or more hours of daily care, and less than 2 years caring/2 or more years caring) were also performed. The effect size was interpreted using the rates in Cohen 
(1988): small ( $\leq 20)$, moderate (21-50), large (51-80) and very large ( $\geq .80)$. Correlational analysis has been also conducted between the variables studied. Finally, a logistic regression analysis with dichotomous variable level of total stress as the variable to be predicted and type of caregiver, level of dependence on the care recipient, hours per day dedicated to caring and years caring as predictor variables, was also performed.

\section{RESULTS}

Reliability was very high in all variables, always in the range of .94-.97. The results of the first bivariate analysis are shown in table 2, with differences in intrusion, avoidance and arousal between nurse and non-nurse caregivers. As it can be seen, stress was significantly higher in non-nurse than nurse caregivers, with higher intrusion, avoidance and arousal. Likewise, the effect size was very large in the three variables with "d" Cohen ranging from .86 to .92 .

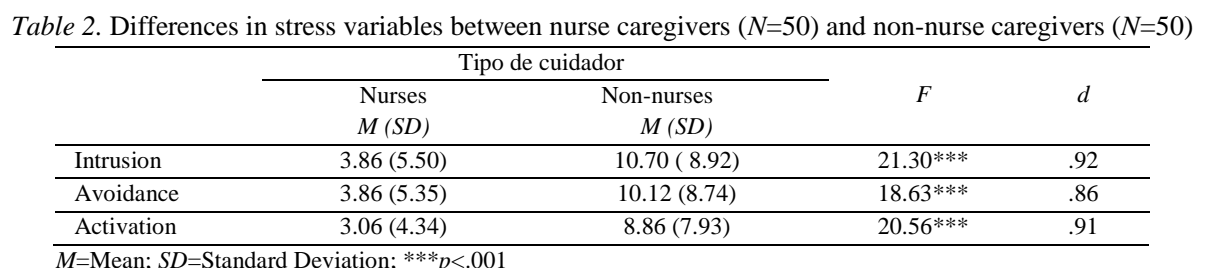

The dependence level of the care recipient has also shown a significant effect on the variables associated with stress, with significant differences between care recipient high and low dependence level, as shown in table 3. Intrusion, avoidance and arousal have been, paradoxically, significantly higher in caregivers caring for a person with low dependence than those caring for a person with high dependency level. Effect sizes in the three variables have been large.

Table 3. Differences in stress variables between caregivers caring for a relative with low dependency level $(N=60)$ and those caring for a relative with high dependency level $(N=40)$

\begin{tabular}{|c|c|c|c|c|}
\hline & \multicolumn{2}{|c|}{ Dependency level } & \multirow[b]{2}{*}{$F$} & \multirow[b]{2}{*}{$d$} \\
\hline & $\begin{array}{c}\text { Low dependency } \\
M(S D)\end{array}$ & $\begin{array}{c}\text { High dependency } \\
M(S D)\end{array}$ & & \\
\hline Intrusion & $9.40(8.91)$ & $4.10(5.53)$ & $11.24 * * *$ & .72 \\
\hline Avoidance & $8.95(8.65)$ & $4.05(5.40)$ & $10.16^{* *}$ & .68 \\
\hline Activation & $7.70(7.72)$ & $3.35(4.74)$ & $10.13 * *$ & .68 \\
\hline
\end{tabular}


Table 4 shows that the number of hours dedicated to the care of the dependent person did not affect the variables associated with stress, with no significant differences in the analysis of variance and small effect sizes.

Table 4. Differences in stress variables between caregivers caring for 1 to 3 hours a day $(N=62)$ and those caring for 4 or more hours a day $(N=38)$

\begin{tabular}{|c|c|c|c|c|}
\hline & \multicolumn{2}{|c|}{ Hours caring } & \multirow[b]{2}{*}{$F$} & \multirow[b]{2}{*}{$d$} \\
\hline & $\begin{array}{c}1-3 \text { hours } \\
M(S D)\end{array}$ & $\begin{array}{c}\geq 4 \text { hours } \\
M(S D)\end{array}$ & & \\
\hline Intrusion & $9.87(8.24)$ & $7.95(8.03)$ & 0.41 & .13 \\
\hline Avoidance & $6.39(7.94)$ & $7.97(7.77)$ & 0.98 & .20 \\
\hline Activation & $5.63(7.18)$ & $6.50(6.76)$ & 0.36 & .12 \\
\hline
\end{tabular}

Differences in stress symptoms between caregivers caring for two or more years and those caring for less than two years are presented in table 5. Intrusion, avoidance and arousal about the task of caring is, paradoxically again, significantly higher in caregivers who had been looking after a dependent relative for less than two years than in those who had been looking after a dependent relative for two or more years. The effect size, being similar in the three variables, is considered high in intrusion and avoidance and moderate in activation.

Table 5. Differences in stress variables between caregivers caring for less than 2 years $(N=55)$ and those caring for 2 or more years $(N=45)$

\begin{tabular}{|c|c|c|c|c|}
\hline & \multicolumn{2}{|c|}{ Years caring } & \multirow{3}{*}{$F$} & \multirow{3}{*}{$d$} \\
\hline & $<2$ years & $\geq 2$ years & & \\
\hline & $M(S D)$ & $M(S D)$ & & \\
\hline Intrusion & $9.24(8.59)$ & $4.88(6.89)$ & $7.54 * *$ & .56 \\
\hline Avoidance & $8.65(8.21)$ & $4.95(7.00)$ & $5.73^{*}$ & .50 \\
\hline Activation & $7.56(7.39)$ & $4.00(6.00)$ & $6.79^{*}$ & .53 \\
\hline
\end{tabular}

The relationship between the variables is shown in table 6. Variables that assess the impact of the stressor, intrusion, avoidance and arousal had significant and very high relationships between them, from .97 to .98 . They also correlate in a moderate but significant way with dependency level so that, following the trend of differential analysis, the lower the dependency level the higher the symptoms associated with stress they suffer when caring for their relative. We also found a significant positive relationship between dependency levels, hours per day dedicated to caring and years caring in the sense that the higher the dependency level of the care recipient the higher the hours per day and years dedicated by the caregiver. 
Table 6. Correlations between the variables

\begin{tabular}{|c|c|c|c|c|c|c|}
\hline & Dependency & Hours caring & Years caring & Intrusion & Avoidance & Activation \\
\hline Dependency & 1 & & & & & \\
\hline Hours caring & $23 *$ & 1 & & & & \\
\hline Years caring & $.21 *$ & $.28 * *$ & 1 & & & \\
\hline Intrusion & $-.26 * *$ & .10 & -.10 & 1 & & \\
\hline Avoidance & $-.25 *$ & .15 & -.10 & $.97 * * *$ & 1 & \\
\hline Activation & $-.26 * *$ & .10 & -.11 & $.98 * * *$ & $.98 * * *$ & 1 \\
\hline
\end{tabular}

Finally, table 7 presents the results concerning the logistic regression analysis step by step, with the sum of the three symptoms of stress as the dependent variable, which we have categorized into two groups taking as cutoff the median, equal to 21 . Predictor variables of symptoms of stress were the type of caregiver (non-nurse/nurse), dependency level of care recipient (low/high dependency level), hours of care per day (1-3/>4 hours) and years caring for the dependent ( $<2$ years $>2$ years). The inclusion of the variable type of caregiver resulted only in the $20 \%$ of variance explained, $B=1.71$ and Wald $=14.10 ; p<.001$ and $O R=5.52$, which means that in non-nurse caregivers the probability of having more symptoms associated with stress was multiplied by 5.52 in comparison with nurse caregivers. The introduction of the dependency level variable improves the model, with an explained variance of $30 \%$, and significant $B$ and Wald statistics $(p<.001$ and $p<.004$, respectively), but mostly increases type of caregiver $O R$ rising to 6.65 and $O R$ for dependency level to 4.01. The two variables in the analysis indicated a higher probability of stress symptoms risk in non-nurses caregivers and those caring for a low level of dependency dependent relative. The inclusion of the third variable, hours of care per day, further improved the regression model by increasing the variance explained to $35 \%$, resulting significant $B$ and Wald statistics in the three variables included, although opposite to type of caregiver and dependency level variables associated to risk, hours of care variable is presented as a protective variable for symptoms of stress, with those caregivers who cared fewer hours per day being $66.3 \%$ less likely to suffer symptoms associated with stress than those who cared for more hours per day. However, even in this case, the percentages of risk of the variables caregiver type and dependency level rose to $O R=7.63$ and $O R=6.22$ respectively. The last variable entered in the regression analysis was that of years caring for the dependent, which again improved the model, explaining $40 \%$ of the variance. The indices $B$ and Wald remain significant for the four variables in the analysis, with increases in $O R$ in all variables in the analysis, with the exception of dependency level that falls to 4.66 having reached 6.22. Accordingly, we can conclude from these results that those that are at higher risk of stress symptoms are non-nurse caregivers who care for a relative with low dependency level for a few hours a day and that have been performing this task for less than two years. 
Table 7. Logistic Regression Analysis

\begin{tabular}{|c|c|c|c|c|c|c|c|c|}
\hline & & \multirow{2}{*}{$R^{2}$} & \multirow{2}{*}{$B$} & \multirow{2}{*}{ Wald } & \multirow{2}{*}{ Sig. } & Exp. & \multicolumn{2}{|c|}{$95 \% \mathrm{IC} / \mathrm{IC} \mathrm{C}_{95 \%} \mathrm{OR}$} \\
\hline & & & & & & $O R$ & Lower & Upper \\
\hline Step 1 & Type of caregiver & .20 & 1.71 & 14.10 & .000 & 5.52 & 2.26 & 13.48 \\
\hline \multirow{2}{*}{ Step 2} & Type of caregiver & .30 & 1.90 & 14.89 & .000 & 6.65 & 2.54 & 17.41 \\
\hline & Dependency level & & 1.48 & 8.41 & .004 & 4.01 & 1.617 & 12.01 \\
\hline \multirow{3}{*}{ Step 3} & Type of caregiver & .35 & 2.03 & 15.64 & .000 & 7.63 & 2.79 & 20.91 \\
\hline & Dependency level & & 1.83 & 10.50 & .001 & 6.22 & 2.06 & 18.77 \\
\hline & Hours caring & & -1.09 & 4.14 & .042 & .337 & .118 & .961 \\
\hline \multirow{4}{*}{ Step 4} & Type of caregiver & 39 & 2.05 & 15.13 & .000 & 7.75 & 2.76 & 21.76 \\
\hline & Dependency level & & 1.54 & 7.16 & .007 & 4.66 & 1.51 & 14.41 \\
\hline & Hours caring & & -1.12 & 4.29 & .038 & .325 & .112 & .940 \\
\hline & Years caring & & 1.02 & 3.85 & .050 & 2.80 & 1.09 & 7.77 \\
\hline
\end{tabular}

\section{DISCUSSION AND CONCLUSIONS}

The work presented here consists of the study of a sample of caregivers caring for a dependent family member at home. However, this sample was special in that half of the caregivers were professional nurses, trained in caring, whilst the other half were non-nurses, without any specific training. The aim of the study was to determine the extent of the effect of the professional training as a nurse, the degree of dependency of the dependent relative, the number of hours per day dedicated to caring and the number of years the caregiver had been looking after the relative, on the symptoms associated to stress in the caregivers.

It is common to find high levels of depressive symptoms, anxiety and even anger and hostility in caregivers who had spent long time looking after dependents with a high level of dependency (Langa et al., 2009, Segui et al., 2008), but the first stages of care, that is, the first years with relatively low level of dependency, are not so well studied. The bivariate results in our study point to a greater impact of the task of caring as a stressor in people not qualified to perform the task compared to those with professional training, such as nurses, and specifically and paradoxically in those who look after relatives with low dependency level and had been performing this task for less than two years.

Multivariate analysis also point to a high impact of care in the early stages, both temporally and in terms of dependence level, in stress symptoms in the caregiver. These results suggest that it is at the beginning of the process of caregiving, a process that can last many years, when stress symptoms appear, mostly as intrusion or reexperiencing of the task of caring, avoidance and high activation in the caregiver.

Apart from the importance of the early stages of the care process, our results lead to another two important conclusions. The first is about the role of professional nurses as providers of informal care for dependent relatives. It seems clear that their training and experience makes them more resistant to the effect of the impact of the stressor on the task of caring for a dependent family member, when compared to 
caregivers without any specific training. Therefore, the role of home health care nurses should clearly go beyond the educational training of the caregiver in the care recipient disease, or recommending drug treatment (Ortiz \& Lozano, 2005; Guerra \& Zambrano, 2013; Delicado et al., 2013), and be included in intervention programs providing caregivers with coping and care management skills.

The second conclusion focuses on the role of stress in the time course of caring for a dependent relative. There is clear evidence that the mental and physical health of the caregiver worsens over time (Artaso et al., 2003) however, our results suggest that the model of stress adaptation can be applied to the caring process. The first two years appear to be particularly stressful in the sample of the present study, with much higher stress symptoms associated to caregivers that had been involved in caregiving for less than two years than those that had been involved in caregiving for two years or more. This supports the hypothesis of an adaptive model to the stress of caring for a dependent relative as proposed by Morris \& Morris (1993). The power of either model would depend especially of the stress-related variables assessed. In the early stages of the task of caring for a dependent family member we found significant levels of intrusion, avoidance and arousal associated with that stressor. Over time caregivers seem to adapt to the care tasks, and stress symptoms seem to diminish. But with continuing of the task throughout the years and with the increased burden associated to an increasing level of dependence, the caregiver's psychological symptomatology in the shape of depression and anxiety and worse general health will increase. Therefore long term stress seems to work as an inverted U-shape, with a significant impact of the stressor in the early and late stages of care.

\section{REFERENCES}

Artaso, B., Goñi, A. \& Biorrun, A. (2003). Cuidados informales en la demencia: predicción de sobrecarga a cuidadoras familiares. Revista Española de Geriatría y Gerontología, 38, 212-18.

Báguena, M.J., Villarroya, E., Beleña, A., Díaz, A. \& Reig, R. (2001). Propiedades psicométricas de la versión española de la escala revisada de impacto del estresor (EIE-R). Análisis y Modificación de Conducta, 27, 581-604.

Baztán, J.J., González, J.I. \& del Ser, T. (1994), Escala de actividades de la vida diaria. En T. del Ser y J. Peña-Casanova (Eds.), Evaluación neuropsicológica y funcional de la demencia, 137-164. Barcelona: Prous Science.

Buck, D., Gregson, B.A., Bamford, C.H., McNamee, P., Farrow, G.N., Bond, J. \& Wright, K. (1997). Psychological distress among informal supporters of frail older people at home and in institutions. International Journal of Geriatric Psychiatry, 12, 737-744.

Cohen, J. (1988). Statistical Power Analysis for the Behavioral Sciences. Hillsdale, N.J.: Erlbaum.

Delicado, M.V., Candel, E., Alfaro, A., López, M. \& García, C. (1013). Interacción de enfermería y cuidados informales de personas dependientes. Atención Primaria, 33, 193-199.

Golimbet, V. \& Trubnikov, V. (2001). Evaluation of the dementia carers situation in Russia. International Journal of Geriatric Psychiatry, 16, 94-99. 
Guerra, M.D. \& Zambrano, E.M. (2013). Relación entre los problemas de salud de los mayores dependientes y la formación de los cuidadores informales. Enfermería Global, 32, 211221.

Horowitz, M.J., Wilner, N.R. \& Álvarez, W. (1979). Impact of Event Scale. A measure of subjective stress. Psychosomatic Medicine, 41, 209-218.

Langa, D., Ariza, S., Martínez, D. \& Olid, E. (2009). Las cuidadoras y los cuidadores de dependientes en el seno de las redes familiares. Una mirada desde la desigualdad. Instituto de Estadística de Andalucía.

Lavoie, J.P. (1995). Support groups for informal caregivers don't work! Refocus the groups or evaluations. Canadian Journal of Aging, 14, 580-595.

Mahoney, F.I. \& Barthel, D.W. (1965). Functional Evaluation: The Barthel Index. Maryland State Medical Journal, 14, 61-65.

Morris, R.G. \& Morris, L.W. (1993). Psychosocial aspects of caring for people with dementia: Conceptual and methodological issues. En A. Burns (Ed.), Ageing and dementia (pp. 251-274). London: Edward Arnold.

Ortiz, A. \& Lozano, C. (2005). El incremento de la prescripción de antidepresivos. Atención Primaria, 35, 152-155.

Roguero, J. (2009). Distribución en España del cuidado formal e informal a las personas de 65 y más años en situación de dependencia. Revista Española de Salud Pública, 83, 393-405.

Schulz, R. \& Beach, S.R. (1999). Caregiving as a risk factor for mortality: The Caregiver Health Effects Study. JAMA, 15, 2215-2219.

Segui, J.D., Ortiz, M. \& de Diego Y. (2008). Factores asociados al estrés del cuidador primario de niños con autismo: sobrecarga, psicopatologías y estado de salud. Anales de Psicología, 24, 100-105.

Received: April 12th, 2014

Modifications received: May 26th, 2014

Accepted: August 11th, 2014 